\title{
Topiramate Versus Propranolol in the Prophylaxis of Migraine in Bangladeshi Population
}

\author{
Muhammad Tayeb ${ }^{1 *}$ \\ Md. Hasanuzzaman ${ }^{2}$ \\ Abul Mansur Md. Rezaul Karim ${ }^{3}$ \\ Mohammad Sanaullah ${ }^{4}$ \\ Md. Ashraful Islam 5
}

'Department of Neurology

Cox's Bazar Medical College

Cox's Bazar, Bangladesh.

${ }^{2}$ Department of Neurology

Chattogram Medical College

Chattogram, Bangladesh.

${ }^{3}$ Department of Medicine

Cox's Bazar Medical College

Cox's Bazar, Bangladesh.

${ }^{4}$ Department of Neurosurgery Cox's Bazar Medical College

Cox's Bazar, Bangladesh.

${ }^{5}$ Department of Anatomy

Cox's Bazar Medical College

Cox's Bazar, Bangladesh.

\section{*Correspondence to:}

Dr. Muhammad Tayeb

Assistant Professor

Department of Neurology

Cox's Bazar Medical College

Cox's Bazar, Bangladesh.

Mobile : +88 01712196976

Email: mtayeb71@gmail.com

Date of Submission ： 05.05.2019

Date of Acceptance ： 30.06 .2019

www.banglajol.info/index.php/CMOSHMCJ

\begin{abstract}
Background : Migraine is primary headache disorder characterized by recurring attacks of pain and associated symptoms. The management modality is still unsatisfactory due to poor understanding of its cause and pathogenesis. To assess the efficacy and safety of low dose Topiramate vs Propranolol in migraine prophylaxis.
\end{abstract}

Materials and methods : A randomized clinical trial including 130 patients with frequent migraine headache $>5$ attacks per month was performed in the out patients Department of Medicine and Neurology, $\mathrm{CMCH}$ for a period of 12 weeks. The patients were randomly divided into two treatment groups - treated by Topiramate $50 \mathrm{mg} /$ day and Propranolol $80 \mathrm{mg} /$ day respectively. Topiramate started with $25 \mathrm{mg} /$ day for 7 days then increased up to 50mg/day in two divided dose. Propranolol started with $40 \mathrm{mg} /$ day for 7 days then increased up to $80 \mathrm{mg} /$ day in two divided dose. The patients were assessed at 0, 8 and 12 weeks of the study.

Results: The Topiramate group showed a reduction in the mean ( $\pm S D$ ) of frequency of migraine attack from 6.95( \pm 2.88$)$ to $1.75( \pm 1.08)$ episode per month, headache days per month from $7.62( \pm 4.14)$ to $1.83( \pm 1.10)$, intensity of headache per attack from $8.98( \pm 1.05)$ to $6.10( \pm 2.50)$ based on VAS scale, duration of headache per episode from $11.56( \pm 9.16)$ to $5.40( \pm 2.97)$ per hour and MIDAS score from $16.19( \pm 3.91)$ to $8.14( \pm 3.93)$. In patient treated with Propranolol, the mean $( \pm S D)$ of monthly frequency of migraine attack declined from $7.09( \pm 2.87)$ to $1.92( \pm 0.98)$ episode per month, headache days per month from 8.17( \pm 4.52$)$ to $1.86( \pm 0.83)$, intensity of headache per attack from $8.47( \pm 1.10)$ to $6.03( \pm 2.05)$ based on VAS scale, duration of headache per episode from 11.16( \pm 8.08$)$ to 5.97( \pm 3.45$)$, MIDAS

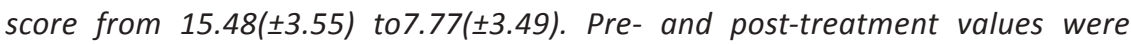
significantly different for individual groups but no significant difference observed between groups.

Conclusion: This study demonstrated that both low dose Topiramate and propranolol could significantly reduce migraine frequency, intensity and duration.

Key words : Migraine; Propranolol; Topiramate.

\section{INTRODUCTION}

Migraine is a common episodic primary headache disorder that is characterized by attacks comprising various combinations of headache and neurological, gastrointestinal and autonomic symptoms. The word 'migraine' is derived from the Greek word hemicrania ${ }^{1}$. Migraine headaches are usually characterized by severe pain on one or both sides of the head accompanied by photophobia (Hypersensitivity to light) phonophobia (Hypersensitivity to sound) and vomiting ${ }^{2}$.

The median frequency of attack of migraine is 1.5 per month and the median duration of an attack is $24 \mathrm{hrs}$, at least $10 \%$ patients have weekly attacks, $20 \%$ have 
attacks lasting 2 or 3 days $^{3}$. Migraine is a common and disabling health problem among children and predominantly young and middle-aged adults. World health Organization (WHO) included the migraine is the global burden of disease ${ }^{4}$. Surveys from the US and elsewhere suggests that $6 \%$ of men and $15 \%-17 \%$ of women experience migraine headache ${ }^{5}$. In perspective of Bangladesh the scenario is nearly same. In a study it was found that different types of headache (38.74\%) were of the highest number (Total 14160 in year 2002) among all the patients who attended in the Neurology outpatient Department, BSMMU, Dhaka ${ }^{6}$.

The pharmacological treatment of migraine can be acute (Abortive) or preventive. Patients with frequent severe headaches often require both approaches. Preventive treatment is used to reduce the frequency, duration or severity of attacks. Additional benefits include improvement of responsiveness to abortive treatment, improvement of function and reduction in disability $^{7}$. Many medication groups are used for preventive treatment of migraine. The choice of preventive medication is empiric, it is influenced by efficacy, adverse effects and patient's coexistence and co-morbid conditions ${ }^{8}$. $\beta$-blocker (Propranolol) has been prescribed for migraine prophylaxis since 1966, when Rabkin et al. discovered its effectiveness in migraine headache in their patients who were being treated for angina pectoris ${ }^{9}$. It is now widely used as cheaper and welltolerated medicine for migraine prophylaxis. It is about 50 percent effective at producing more than 50 percent reduction in attack frequency ${ }^{10}$. Propranolol is well tolerated in general; it is associated with a variety of adverse effects such as bradycardia, hypotension, bronchospasm, gastrointestinal complaints \& vertigo. This wide range of side-effects may limit its use for some patients.

Anti-convulsant drugs for migraine prophylaxis have been tested since 1970 with carbamazepine as the first drug of this group $^{11}$. Topiramate was approved by the FDA in the USA for migraine treatment since 2004. Asides for its use as an anti epileptic, Topiramate in migraine treatment is its most common use. Multiple clinical trials have been published in literature comparing the efficacy of Topiramate with placebo ${ }^{12,13,14,15}$. Topiramate has shown the efficacy, safety \& reduces the frequency of migraine attack. Three large clinical trials have unequivocally established its effectiveness at doses from $50 \mathrm{mg}$ to $200 \mathrm{mg}$ daily ${ }^{14,16,1}$. A randomized, double-blind, clinical trials demonstrated that low dose Topiramate could significantly reduce migraine headache frequency, intensity, and duration ${ }^{17,18}$. Topiramate has numerous effects on the central nervous system. It enhances the inhibitory effects of GABA and block the excitatory effect of glutamate. It also stops the repetitive firing of sodium channels, thus reducing calcium channel activity and inhibits carbonic anhydrase. Such mechanism may possibly explain its effects in pain relief ${ }^{19}$. Several studies indicated the role of high dose (100-200mg/day) Topiramate in migraine prophylaxis. However, for such high doses, there are usually significant side effects like parasthesia, fatigue, memory disturbances, loss of appetite, and weight loss, nausea and taste perversion. As a result, many patients do not tolerate high dose Topiramate ${ }^{20,21}$.

The present study will perform to evaluate the efficacy of lowdose Topiramate in migraine prophylaxis and compare it with Propranolol.

\section{MATERIALS AND METHODS}

This study was a randomized controlled trial carried out in the out patient Department of Medicine and Neurology, Chattogram Medical College \& Hospital, Chattogram, from November 2010 to October 2011 for duration of 01(one) year. The patients who presented with headache in the Medicine and Neurology OPD at $\mathrm{CMCH}$ was enrolled in this study. A total number of 130 patients presented with migraine were enrolled in this study according to the selection criteria. It was a Purposive sampling technique.

\section{Inclusion criteria}

i) Diagnosed cases of migraine (With or without aura) according to the IHS criteria

ii) Frequency of five or more migraine headache attack per month during a 3-month period before entry

iii) Age at entry 16-50 years

iv) The concomitant migraine prophylactics withdrawn 1month prior to entry into this trial.

\section{Exclusion criteria}

i) Patient having any suspicion of having headache other than migraine which needed evaluation by imaging

ii) Women having pregnancy or wanted to conceive in next 6 months

iii) Patient having known bronchial asthma, heart block, heart failure, liver disease, renal stones, or malignant conditions.

All selected patients were informed about the treatment options and written witnessed consent was taken from them. The patients were divided into two groups named as Group-A and Group-B. Randomization was done on a 1:1 basis to receive either topiramate $(50 \mathrm{mg} /$ day $)$ or propranolol (80mg/day). The patients were treated according to allotted group. Group A participants were treated by Propranolol (80mg) [Brand name- Tab. Indever (40mg)]. Group B participants were treated by Topiramate $(50 \mathrm{mg})$ [Brand nameTab. Etopira (25mg)].

Topiramate was started at a dose of $25 \mathrm{mg}$ per day for 7 days then increased up to $50 \mathrm{mg}$ per day in two divided doses. Propranolol was started at a dose of $40 \mathrm{mg}$ per day for 7 days then increased up to $80 \mathrm{mg}$ per day in two divided doses. Patients were followed up at 8 wks and 12 wks after starting preventive treatment. Headache frequency, headache days, pain scale and MIDAS score were noted in at presentation and at follow-up . The side effects of the both drugs were monitored by observing the Group-A and Group-B. On first visit patients' frequency of headache, total headache days, pain intensity 
(VAS scale) and MIDAS score in the month before starting treatment were recorded. The study subjects or his/her relative who is a literate person were asked to maintain a headache dairy to note migraine attack date, duration of headache (Persistent of headache per episode) (Headache lasting $<24 \mathrm{hrs}-$ 1 day, $>24 \mathrm{hrs}$ to $<48 \mathrm{hrs}-2$ days, $>48 \mathrm{hrs}$ to $<72 \mathrm{hrs}-3$ days), pain intensity and rescue medication take time. They were convinced to come for follow up after $8 \mathrm{wks}$ and $12 \mathrm{wks}$ of initiation of therapy. In each visit, headache attack frequency, total headache days, pain intensity and rescue medication needed were recorded. MIDAS score was calculated by the physician himself in presence of the patient. Patient's pulse, blood pressure, and body weight were also recorded in each visit. Any adverse effects of drug was also recorded.

\section{RESULTS}

During the study period, a total of 350 fresh headache cases were screened. Of them 180 patients met the diagnostic criteria of migraine according to International Headache Classification Committee (IHCC, 2004). Out of them 130 patients met the inclusion and exclusion criteria to be selected as study subjects. The study subjects were randomly selected for prophylactic treatment with either Topiramate $(50 \mathrm{mg})$ or Propranolol (80mg). During the follow up period 01 patient from Propranolol group and 02 patients from Topiramate group were excluded from the study due to non compliance of the medication and failure to attend at the follow-up. As such, ultimately 64 patients in Propranolol group and 63 patients in Topiramate group completed the study. Occasional minor side effects were tolerated well by members of both the groups.

Following tables and figures show detailed socio-demographic character of the study population and outcome of treatment after 12 weeks:

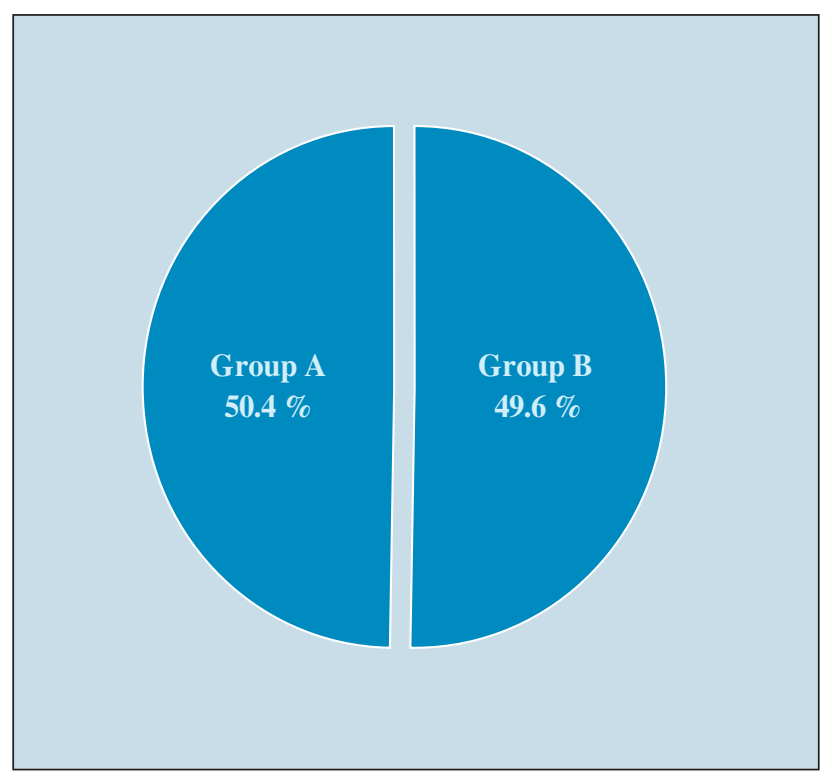

Figure 1 : Distribution of the study groups
Table I: Distribution of the age groups and sex among the study groups (With $\chi^{2}$ test significance)

\begin{tabular}{|c|c|c|c|c|c|c|}
\hline \multirow[t]{3}{*}{ Age In Groups } & \multicolumn{4}{|c|}{ Study Groups } & \multicolumn{2}{|c|}{ Total } \\
\hline & \multicolumn{2}{|c|}{ Group A } & \multicolumn{2}{|c|}{ Group B } & & \\
\hline & n & $\%$ & n & $\%$ & $\mathrm{n}$ & $\%$ \\
\hline$<20$ Years & 19 & 29.7 & 17 & 27.0 & 36 & 28.3 \\
\hline 20 - 30 Years & 32 & 50.0 & 34 & 54.0 & 66 & 52.0 \\
\hline$>30$ Years & 14 & 21.8 & 11 & 17.4 & 25 & 19.7 \\
\hline Total & 65 & 100.0 & 62 & 100.0 & 127 & 100.0 \\
\hline \multicolumn{7}{|c|}{$\chi^{2}$ value $=3.033 . \mathrm{df}=2 . \mathrm{p}=0.219$. Not Significant $(\mathrm{p}>0.05)$} \\
\hline \multirow[t]{3}{*}{ Sex } & \multicolumn{4}{|c|}{ Study Groups } & \multicolumn{2}{|c|}{ Total } \\
\hline & \multicolumn{2}{|c|}{ Group A } & \multicolumn{2}{|c|}{ Group B } & & \\
\hline & n & $\%$ & n & $\%$ & $\mathrm{n}$ & $\%$ \\
\hline Male & 24 & 37.5 & 12 & 19.0 & 36 & 28.3 \\
\hline Female & 40 & 62.5 & 51 & 81.0 & 91 & 71.7 \\
\hline Total & 64 & 100.0 & 63 & 100.0 & 127 & 100.0 \\
\hline Male : Female $\mathrm{F}$ & \multicolumn{2}{|c|}{$1: 1.7$} & \multicolumn{2}{|c|}{$1: 4.2$} & \multicolumn{2}{|c|}{$1: 2.5$} \\
\hline
\end{tabular}

$\chi^{2}$ value $=5.322 . \mathrm{df}=1 . \mathrm{p}=0.021$. Significant $(\mathrm{p}<0.05)$

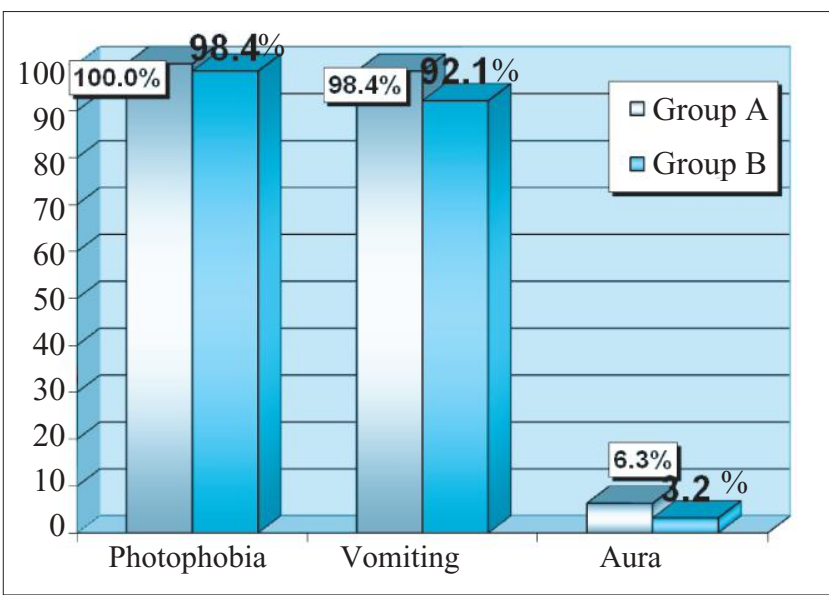

Figure 2 : Distribution of positive clinical presentation among the study groups

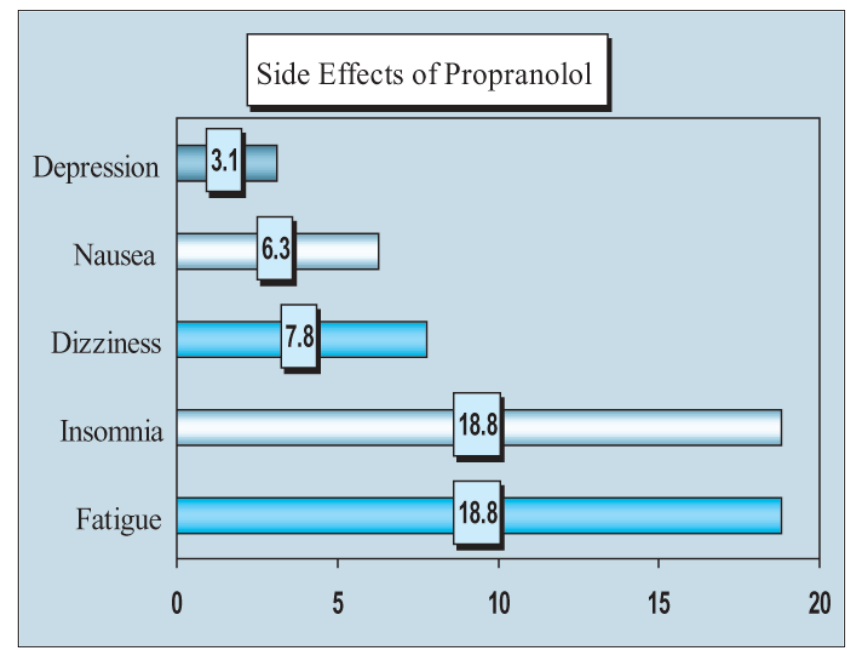

Figure 3 : Distribution of side effects of Propranolol ( $n=64)$ 


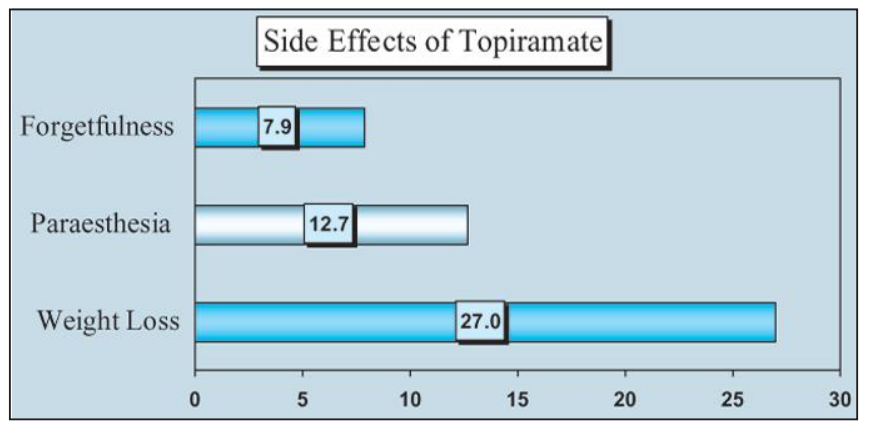

Figure 4 : Distribution of side effects of Topiramate $(n=63)$

Table II shows significant reduction of headache frequency, headache days, intensity of headache, duration of headache per episode and MIDAS score from baseline (Before treatment) visit to 12 weeks after migraine prophylaxis $(p<0.001)$.

Table II : Assessment of patients at the end of 12-weeks follow-up

\begin{tabular}{|c|c|c|c|c|c|}
\hline Study Groups & n & $\begin{array}{l}\text { Score } \\
\text { Initial Visit } \\
(\text { Mean } \pm \text { SD) }\end{array}$ & $\begin{array}{l}\text { Final Visit } \\
(\text { Mean } \pm \text { SD) }\end{array}$ & \multicolumn{2}{|c|}{$\begin{array}{c}\text { Percent } \\
\text { Decrease of } \\
\text { Mean from } \\
\text { Initial to } \\
\text { Final Visit }\end{array}$} \\
\hline \multicolumn{6}{|c|}{ Frequency of Attack/Month } \\
\hline Group A (Propranolol) & 64 & $7.09 \pm 2.87$ & $1.92 \pm 0.98$ & -72.92 & $p=<0.001$ \\
\hline Group B (Topiramate) & 63 & $6.95 \pm 2.88$ & $1.75 \pm 1.08$ & -74.82 & $\mathrm{p}=<0.001$ \\
\hline \multicolumn{6}{|l|}{ Headache Days/Month } \\
\hline Group A (Propranolol) & 64 & $8.17 \pm 4.52$ & $1.86 \pm 0.83$ & -77.23 & $p=<0.001$ \\
\hline Group B (Topiramate) & 63 & $7.62 \pm 4.14$ & $1.83 \pm 1.10$ & -75.98 & $\mathrm{p}=<0.001$ \\
\hline \multicolumn{6}{|l|}{$\begin{array}{l}\text { Intensity of Headache } \\
(V A S) / A t t a c k\end{array}$} \\
\hline Group A (Propranolol) & 64 & $8.47 \pm 1.10$ & $6.03 \pm 2.05$ & -28.81 & $p=<0.001$ \\
\hline Group B (Topiramate) & 63 & $8.98 \pm 1.05$ & $6.10 \pm 2.50$ & -32.07 & $p=<0.001$ \\
\hline \multicolumn{6}{|l|}{$\begin{array}{l}\text { Duration of Headache } \\
\text { per Episode }\end{array}$} \\
\hline Group A (Propranolol) & 64 & $11.16 \pm 8.08$ & $5.97 \pm 3.45$ & -46.50 & $p=<0.001$ \\
\hline Group B (Topiramate) & 63 & $11.56 \pm 9.16$ & $5.40 \pm 2.97$ & -53.29 & $p=<0.001$ \\
\hline \multicolumn{6}{|l|}{ MIDAS Score } \\
\hline Group A (Propranolol) & 64 & $15.48 \pm 3.55$ & $7.77 \pm 3.49$ & -49.81 & $p=<0.001$ \\
\hline Group B (Topiramate) & 63 & $16.19 \pm 3.91$ & $8.14 \pm 3.93$ & -49.72 & $p=<0.001$ \\
\hline
\end{tabular}

* Paired sample $\mathrm{t}-$ test. HS = Highly Significant $(\mathrm{p}<0.001)$.

Table III : Assessment of patients at different visits

\begin{tabular}{lccc}
\multicolumn{1}{c}{$\begin{array}{c}\text { Scores } \\
\text { (Mean } \pm \text { SD) }\end{array}$} & \multicolumn{2}{c}{ Study Groups } & p Value \\
& Group A & Group B & \\
& & & \\
Frequency of Attack & & & \\
First Visit & $7.09 \pm 2.87$ & $6.95 \pm 2.88$ & 0.782 \\
& & & NS \\
Second Visit & $3.83 \pm 1.70$ & $3.63 \pm 1.67$ & 0.520 \\
& & & NS
\end{tabular}

Third Visit

$$
1.92 \pm 0.98 \quad 1.75 \pm 1.08
$$

0.338

NS

Headache Days/month

$\begin{array}{lccc}\text { First Visit } & 8.17 \pm 4.52 & 7.62 \pm 4.14 & 0.474 \\ & & & \mathrm{NS} \\ \text { Second Visit } & 3.73 \pm 1.72 & 3.79 \pm 1.81 & 0.850 \\ & & & \mathrm{NS} \\ \text { Third Visit } & 1.86 \pm 0.83 & 1.83 \pm 1.10 & 0.845 \\ & & & \mathrm{NS} \\ \text { Intensity of Headache (VAS) } & & \\ \text { First Visit } & 8.47 \pm 1.10 & 8.98 \pm 1.05 & 0.008 \\ & & & \mathrm{HS} \\ \text { Second Visit } & 7.09 \pm 1.14 & 7.41 \pm 1.09 & 0.109 \\ & & & \mathrm{NS} \\ \text { Third Visit } & 6.03 \pm 2.05 & 6.10 \pm 2.50 & 0.875 \\ & & & \mathrm{NS}\end{array}$

Duration of Headache

\section{Per Episode}

First Visit

$$
11.16 \pm 8.08
$$

$11.56 \pm 9.16$

0.795

Second Visit

$$
7.16 \pm 3.04
$$

$8.75 \pm 7.69$

NS

Third Visit

$$
5.97 \pm 3.45
$$

$5.40 \pm 2.97$

\section{MIDAS Score}

\begin{tabular}{lccc} 
First Visit & $15.48 \pm 3.55$ & $16.19 \pm 3.91$ & 0.289 \\
& & & NS \\
Second Visit & $11.83 \pm 3.57$ & $12.16 \pm 3.78$ & 0.613 \\
& & NS \\
Third Visit & $7.77 \pm 3.49$ & $8.14 \pm 3.93$ & 0.568 \\
& & NS \\
\hline - Independent samples $\mathrm{t}-$ test. & \\
- NS = Not Significant $(\mathrm{p}>0.05)$; HS $=$ Highly Significant $(\mathrm{p}<0.01)$. \\
DISCUSSION
\end{tabular}

Migraine is an important cause of recurrent headache and headache related disabilities in general population affecting children, adolescent and adult. Its exact pathophysiology is poorly understood, as such, its effective and curative treatment is not possible. Abortive therapy has different options and more or less successful.

In this study, majority (52\%) of the subjects were between the 20 to 30 years of age. According to Panda et al, most of the migraineurs were between 12 to 40 years ${ }^{22}$. Prevalence peaked in middle life and was lower in adolescents and those older than 60 years $^{23}$. According to Roper and Brown (2005), more than 80 percent of the migraineurs were under 30 years of age $\mathrm{e}^{24}$.

Female occupied the main bulk $(71.7 \%)$ of the study subjects with a female to male ratio $2.5: 1$, which is near to the ratio of 3:1 (Approximately) shown by panda et $\mathrm{al}^{22}$. Lipton et al. showed that one year period of migraine prevalence was $11.7 \%$ $(17 \% \text { women and } 5.6 \% \text { in men })^{23}$. 
The most common presenting complaints other than headache among study subjects include vomiting photophobia and phonophobia.

Out of all patients of Topiramate group $79.3 \%$ had moderately, $4.8 \%$ had very little and $15.9 \%$ had extremely affected quality of life. In Propranolol group $90.6 \%$ had moderately, $1.6 \%$ had very little and $7.8 \%$ had extremely affected quality of life.

In this study, Topiramate group has $69.8 \%$ and Propranolol group has $65.6 \%$ positive family history of migraine respectively. No significant difference was observed between Topiramate and Propranolol group in chi-square test ( $p>0.05)$.

Mean $( \pm \mathrm{SD})$ Frequency of migraine attack per month before starting preventive therapy was $6.95( \pm 2.88)$ in Topiramate group and $7.09( \pm 2.87)$ in Propranolol group. The difference in frequency between groups was not significant $(\mathrm{p}>0.50)$. Frequency was reduced to $1.75( \pm 1.08)(74.82 \%)$ in Topiramate group and $1.92( \pm 0.98)(72.92 \%)$ in Propranolol group after 12 weeks of therapy. Reduction of frequency of headache was significant in both group but difference between group was not significant.

Mean $( \pm \mathrm{SD})$ Headache days per month before starting preventive treatment were $7.62( \pm 4.14)$ for Topiramate group and $8.17( \pm 4.52)$ for Propranolol group. After 12 weeks of preventive therapy, mean $( \pm \mathrm{SD})$ headache days reduced to 1.83 $( \pm 1.10)(75.98 \%)$ in Topiramate and $1.86( \pm 0.83)(77.23 \%)$ in Propranolol treated patients.

Intensity of headache per attack measured by VAS scale was $8.98( \pm 1.05)$ in Topiramate group and $8.47( \pm 1.10)$ in Propranolol group before starting treatment. After 12 weeks of preventive therapy, Intensity of headache decreased to 6.10 $( \pm 2.50)(32.07 \%)$ in Topiramate and $6.03( \pm 2.05)(28.81 \%)$ in Propranolol group. The reduction of intensity of headache was significant $(p<0.001)$ for each group but there was no significant difference in between the groups ( $p>0.50)$.

Mean $( \pm \mathrm{SD})$ duration of headache per episode before starting treatment was $11.56( \pm 9.16) \mathrm{hrs}$. in Topiramate group and $11.16( \pm 8.08)$ hrs. in Propranolol group. After 12 weeks of preventive treatment, duration of headache per episode was reduced to $5.40( \pm 2.97)(53.29 \%)$ in Topiramate group and 5.97 ( \pm 3.45$)(46.50 \%)$ in Propranolol group. Reduction of duration of headache per episode was significant $(p<0.001)$ in each group.

Mean $( \pm$ SD) pre-treatment MIDAS score was $16.19( \pm 3.91)$ in Topiramate group which was reduced to $8.14( \pm 3.93)(49.72 \%)$ after 12 weeks of treatment. On the other hand, mean $( \pm$ SD) pre-treatment MIDAS score was $15.48( \pm 3.55)$ in Propranolol group which was reduced to $7.77( \pm 3.49)(49.81 \%)$ after 12 weeks of treatment. Pre- and post-treatment values were significantly different $(\mathrm{p}<0.001)$ for individual groups but no significant difference observed between groups ( $>>05)$.

There is no statistically significant difference between the two groups according to baseline headache character. In the current study both Topiramate and Propranolol decreased monthly headache frequency, intensity and duration of migraine.

Ashtari F et al. assessed the efficacy and safety of low dose Topiramate in migraine prophylaxis vs Propranolol in a randomized double blind clinical trial including 62 patients with frequent migraine headache (3 attacks per month) was performed for a period of 8 weeks ${ }^{17}$. The patients were randomly divided into two groups- treated by Topiramate $50 \mathrm{mg} /$ day and Propranolol $80 \mathrm{mg} /$ day respectively. The patients assessed at o, 4 and 8 wks of the study. They showed that Topiramate group showed a reduction in the mean $( \pm \mathrm{SD})$ of monthly migraine frequency from $6.07( \pm 1.89)$ to $1.83( \pm 1.39)$ episodes per month, headache intensity from $7.1( \pm 1.45)$ to $3.67( \pm 2.1)$ based on the visual analogue scale, and headache duration from $16.37( \pm 7.26)$ to $6.23( \pm 5.22)$ hours $(p>0.001)$. In the patients treated with Propranolol, the mean $( \pm \mathrm{SD})$ of monthly headache frequency declined from $5.83( \pm 1.98)$ to 2.2 $( \pm 1.67)$ per month, headache intensity lessened from 6.43 $( \pm 1.6)$ to $4.13( \pm 1.94)$ and headache duration decreased from $15.10( \pm 6.84)$ to $7.27( \pm 5.46)$ hours $(\mathrm{p}<0.001)$. They concluded that their study demonstrated both low-dose Topiramate and Propranolol could significantly reduce migraine headache frequency, intensity and duration.

During the follow up, patients complained of fatique, insomnias, dizziness, nausea and depression in Propranolol group. In Topiramate group, patients complained of having parasthesia, forgetfulness \& weight loss. None of the effects caused withdrawal of medication.

\section{CONCLUSION}

From this study, it may be concluded that Topiramate is equally effective as Propranolol in migraine prophylaxis. Its side effects are minimum and it may be prescribed specially for the patients where beta blocker are contra-indicated.

\section{DISCLOSURE}

All the authors declared no competing interest. 


\section{REFERENCES}

1. $\quad$ Silberstein SD. Migraine.Lancet. 2004;363:381-391.

2. Cephalalgia. 2004; 24(Suppl. 1):30-31,http:/216.25.100.131/upload/ct classic II main no print.pdf.

3. Stewart WF, Lipton RB, Celentano DD. Prevalence of migraine headache in the USA: Relation to age, income, race and other sociodemographic factors. JAMA. 1992;267:64-69.

4. World Health Organization. The World Health Report. Mental Health: New Understanding. New Hope. http:/www.who.int.whr/2001/en/index.html. Accessed January 12,2009.

5. Stewart WF, Shechter A, Lipton RB. Migraine heterogeneity. Disability, pain intensity, and attack frequency and duration. Neurology. 1994;44(Suppl 4):24-39.

6. Islam RRH, Zahidur BM, Ullah MAKMA. Disease profile of Neurology outpatient department of BSMMU on the year 2002. Bangladesh journal of neuroscience. 2003;19(2):73-76.

7. Silberstein SD. Preventive treatment of migraine. Trends pharmacol Sci. 2006;27:410-415.

8. Silberstein SD. Headache in clinical practice. In: Taylor, Francis, editors. Headache in clinical practice. $2^{\text {nd }}$ ed. Oxford: Oxford University Press. 2002;96-101.

9. Rabkin R, Stables DP, Levin NW. The prophylactic value of Propranolol in angina pectoris. Am J Cardiol. 1996;18: 370-380.

10. Gray RN, McCrory DC. Drug treatment for prevention of migraine headache. Prepared for the US Agency for Health Care Policy and Research. (Technical Review 2.3). 1999.

11. Rompel H, Bauermeister PW. Aetiology of migraine and prevention with carbamazepine: Result of a double- blind crossover study. S Afr Med J. 1970;44:75-80.

12. Brandes JL, Saper JR, Diamond M the MIGR-002 Study Group. Topiramate for migraine prevention: A randomized controlled trial. JAMA. 2004;291:965-973.

13. Edwards KR, Glantz MJ, Norton JA. Cross N-Prophylactic treatment of episodic migraine with Topiramate: A double-blind, placebocontrolled trial in 30 patients. Cephalalgia. 2000;20:316.

14. Amico D, Grazzi L, Usai S. Topiramate in migraine prophylaxis. Neurol Sci. 2005;26 (Suppl2).

15. Storey JR, Calder CS, Hart DE, Potter DI. Topiramate in migraine prevention: A double-blind, placebo-controlled study. Headache. 2001;41:968-975.

16. Diener HC, Tfelt-Hansen P, Dahlof C, MIGR-003 Study Group. Topiramate in migraine prophylaxis-results from a placebo-controlled trial with Propranolol as an active control. J Neurol. 2004; 251:943-950.

17. Ashtari F. Shaygannejad V, Akbari M. A double-blind, randomized trial of low- dose Topiramate vs Propranolol in migraine prophylaxis. Acta Neurologica Scandinavica. 2008;118:301-305.

18. Gupta P, Singh S, Goyal V, Shukla G, Behari M. Low- dose Topiramate vs lamotrigine in migraine prophylaxis(the Lotolamp study). Headache. 2007;47:402-412.

19. White HS. Molecular pharmacology of Topiramate: managing seizures and preventing migraine. Headache. 2005;45:48-56.

20. Brandes JL. Practical use of Topiramate for migraine prevention. Headache, 2005;45(Suppl.):s66-73.

21. Huppertz HJ, Quiske A, Schulze-Bonhage A. Cognitive impairments due to add-on therapy with Topiramate. Nervenarzt. 2001;72:275-280.

22. Samhita P, Manjari T. Clinical profile of Migraineurs in a Referral Centre in India. JAPI. 53:111-115.

23. Lipton RB, Bigal ME, Diamond M, AMPP Advisory Group. Migraine prevalence, disease burden, and the need for preventive therapy. Neurology. 2007;68:343-349.

24. Ropper AH, Brown RH. Headache and other craniofacial pains. In: Adams and Victor's principles of neurology. $8^{\text {th }}$ ed. New York: McgrawHill Companies. 2005;144-167. 